\title{
CONTRIBUIÇÕES PARA UMA GEOGRAFIA DA VIDA COTIDIANA: JOÃO DO RIO, UM FLÂNEUR DOS TRÓPICOS
}

\section{Contributions to a geography of everyday life: João do Rio, a flâneur of the tropics}

\author{
Anael Ribeiro Soares \\ Mestre em Geografia Humana pela Universidade de São Paulo \\ Professor da rede estadual de ensino do estado do Ceará \\ anael.rs@gmail.com
}

Artigo recebido para publicação em 27/11/2019 e aceito em 06/04/2020

DOI: $10.12957 /$ tamoios.2020.45339

\begin{abstract}
Resumo
O presente estudo se propõe a analisar parte do que foi produzido por João do Rio entre o fím séc. XIX e o início do XX como contribuições aos estudos da Geografia urbana brasileira, tendo como recorte espacial a metrópole carioca sob o véu da belle époque, a partir de uma categoria de análise central: a vida cotidiana. $\mathrm{O}$ arsenal teóricometodológico no qual se buscou subsídios estão associados aos estudos no interior da teoria crítica. Ao final, ao aproximarmos a obra de João do Rio com as condições objetivas no espaço-tempo a partir das quais sua arte ganhava corporeidade, observamos o lugar que ocupa o cotidiano em suas crônicas, bem como papel da rua enquanto lócus dos encontros.
\end{abstract}

Palavras-chave: Arte; João do Rio; Vida Cotidiana.

\begin{abstract}
Abstratc
The present article proposes to analyze part of what was produced by João do Rio between the end century. XIX and the beginning of the XX as contributions to the studies of brazilian urban geography, having as a spatial clipping the Rio metropolis under the veil of belle époque, from a category of central analysis: everyday life. The theoretical-methodological arsenal in which subsidies were sought are associated with studies within critical theory. In the end, as we approached the work of João do Rio with the objective conditions in space-time from which his art gained corporeity, we observed the place that daily life occupies in his chronicles, as well as the role of the street as a locus of the Meetings.
\end{abstract}

Keywords: Art, João do Rio, Everyday life. 


\section{Introdução}

A produção do conhecimento geográfico não está circunscrita ao exercício intelectual do Geógrafo, esse conhecimento ganha corpo também quando se busca manter um diálogo profícuo para além da cientificidade, aproximando-se, inclusive, da arte. A despeito de não ser exatamente essa nossa empreitada (travar um diálogo com outras áreas produtores de saber) - embora indiretamente o perpasse -, argumentamos em favor da incorporação de um espírito crítico e criativo, desviando-se de anacronismos e renegando concepções científicas eurocêntricas. Assim é possível lançar luz sobre outras geografias para além daquela concebida a partir dos centros da produção científica. Eis aí nosso intento: privilegiar as geografias dos trópicos, forjadas a partir da nossa própria realidade socioespacial na condição de periferia do conhecimento científico. Dessa forma, o presente ensaio segue na contramão daquela sobreposição do centro sobre a periferia do ponto de vista da produção do conhecimento científico, teoria eurocêntrica cuja difusão coube particularmente a Basalla (1967).

Tal como no nascimento da Geografia europeia no seio modernidade, sob a perspectiva da escala brasileira a institucionalização dela ocorre na medida em que o Estado se fortalece, paralelamente a consolidação política da burguesia industrial (MORAES, 1991). Nesse sentido, a Geografia brasileira tende a desempenhar uma tarefa ideológica voltada para criação de uma identidade nacional, bem como para o desenvolvimento das forças produtivas, ao passo em que possibilita também o reconhecimento das potencialidades do território em conformação. Assim, ao passo em que é institucionalizada, a geografia torna-se um saber instrumental, essencial para os Estados-maiores, como certa feita argumentara Lacoste (2001).

Diante disso, incorre-se numa interpretação segundo a qual tudo que foi produzido de natureza geográfica no Brasil até pelo menos 1930 compõe uma espécie de acervo pré-científico. Tal periodização, contudo, dá margem para uma tese controversa de que a Geografia só ganha existência no Brasil, de fato, a partir da década de 1930. Não obstante, Quaini (apud MORAES, 1991, p.171) nos adverte: "não se deve confundir a história da disciplina com história da Geografia em si mesma."

Contrariando o consenso, pesquisas recentes tem demonstrado que existia atividade científica de cunho geográfico no Brasil durante o século XIX, como, por exemplo, as atividades exercidas nos de institutos de pesquisa, além dos trabalhos de natureza independente (SOUZA NETO, 2001; COUTINHO, 2011). 
Por isso, para mapearmos a história da Geografia brasileira, devemos partir de alguns pressupostos basilares, a saber: há geografias para além do centro; o conhecimento geográfico não é de propriedade privada dos Geógrafos; marcos históricos, muitas vezes, ofuscam a atividade científica porque dão visibilidade a um recorte do processo histórico em detrimento de outras histórias, por vezes encobertas pela cortina da oficialidade. (BENJAMIN, 1994)

Endossando outros estudos e associando-se a um rol deles que tem rompido com paradigmas evolucionistas no estudo das ciências, este ensaio faz o resgaste de um contributo para o que pode ser considerado uma "geografias dos trópicos", aqui concebida num diálogo híbrido entre arte (literatura) e jornalismo.

A partir desses pressupostos supracitados que se valida à pertinência desse ensaio, cujo objetivo se propõe a analisar parte do que foi produzido por João do Rio entre o fim séc. XIX e o início do XX enquanto contribuições aos estudos da Geografia urbana brasileira, tendo como recorte espacial a metrópole carioca sob o véu da belle époque, a partir de uma categoria de análise central: a vida cotidiana. Para tanto, autores como Lukács $(1992,2009)$ e Lefebvre (1991) serão de grande valia, tanto no aspecto estético quanto na interface entre espaço urbano/cotidiano.

A geografia do cotidiano das obras de João do Rio contempla o sujeito na relação intrínseca com seu espaço vivido, não em termos de localização, mas do ponto de vista da totalidade concreta na medida em que ele interage objetivamente com o mundo. Isso implica em considerar o sujeito total à luz do processo histórico como construção social, estando aberto ao devir, sob a perspectiva de mediações objetivas que o perfazem na condição também de produtor do seu lugar, mesmo que atravessado por contradições. (CARLOS, 1998)

A título de estruturação, inicialmente, pretende-se situar o leitor quanto à figura de João do Rio mediante o contexto histórico-espacial dentro do qual ele se encontrava imerso. Em seguida, tratar-se-á da relação de João do Rio com a metrópole carioca, cujas transformações o levaram a escrever crônicas, contos, livros, dentre os quais, "A alma encantadora das ruas". É justamente esta última obra será objeto de reflexão no desfecho do presente ensaio. 


\section{João do Rio, um flâneur carioca}

Ao invés de um João do Rio, devemos começar a tratar de vários deles. O jornalista, cronista, contista, antropólogo - geógrafo? -. Acontece que João Paulo Emílio Cristóvão dos Santos Coelho Barreto, mais conhecido simplesmente como João do Rio, exerceu o papel de jornalista, cronista, escritor, além outros papéis, vivendo no Rio de Janeiro durante a virada do século XIX para o XX. Martins (2012, p.14) sintetiza bem o que representa a obra de João do Rio ao dizer que “(...) constitui o mais minucioso, vivo e válido dos retratos de uma época, através dos múltiplos aspectos da vida carioca, nas duas primeiras décadas do século XX."

De todas suas características no ofício da linguagem, por ora, ficamos com o João cronista da cidade, ou melhor, da metrópole carioca, cuja tarefa consistia em narrar tudo quanto experienciava na belle époque carioca através das suas flanâncias, à deriva pelos morros:

\footnotetext{
As pequenas profissões!... É curioso!

As profissões ignoradas. Decerto não conheces os trapeiros sabidos, os apanha-rótulos, os selistas, os caçadores, as ledoras de buena dicha. Se não fossem o nosso horror, a diretoria de Higiene e as blagues das revistas de ano, nem os ratoeiros seriam conhecidos.

- Mas, senhor Deus! É uma infinidade, uma infinidade de profissões sem academia! Até parece que não estamos no Rio de Janeiro... Oh, essas pequenas profissões ignoradas, que são partes integrantes do mecanismo das grandes cidades! (RIO, 2007, p.51)
}

Ao enfatizar o quanto são ignoradas tais profissionais, a despeito da relevância delas, João do Rio deixa entrever a divisão social do trabalho, além do fato da urbanização capitalista ser um fenômeno classista, pois nela as cidades surgem senão com fins fetichizantes, resultante da contingência da (re)produção do capital na medida em que são operacionalizados por um determinado grupo social geralmente hegemônico. Nas palavras de Harvey (2008, p.85), historicamente a urbanização “desempenhou um papel decisivo na absorção de capitais excedentes, em escala geográfica sempre crescente, mas ao preço do explosivo processo de destruição criativa que tem desapropriado as massas de qualquer direito à cidade." A propósito dessa destruição criativa assinalada por Harvey, vale frisar que ela não acompanhou somente a Paris do séc. XIX, mas também esteve presente na então metrópole carioca no início do séc.XX.

Enquanto no final do séc. XIX, na França, o barão Hausmann promove uma reforma urbana em Paris, expulsando os pobres e miseráveis do centro, no início do 
séc.XX o Rio de Janeiro vai igualmente ser submetido ao processo de "modernização", realizada pelo então prefeito Pereira Passos.

Entre 1902 e 1906, o centro do Rio de janeiro vai sofrer uma reforma urbana, através daquilo que ficou conhecido popularmente como bota-abaixo, objetivando ampliar as vielas, ruas estreitas, de maneira a prepara-las para modernidade e a civilização. A avenida central, com mais de 25 metros, vai suprimir os encontros para atender ao tráfego de automóveis, símbolo do progresso (IVO, 2009; FERREIRA, 2012) Ainda podemos arrolar como elementos desse processo de modernização na metrópole carioca, recorrendo a Martins (2012, p.15):

\begin{abstract}
A eletricidade substituía os bicos de gás; os bondes de burros cediam lugar aos tramways da Companhia Jardim Botânico; os velhos tílburis e fiacres iam aos poucos desaparecendo, para dar lugar aos primeiros automóveis; o cinematográfogo fazia concorrência ao teatro; a Europa curvava-se ante o Brasil, com as descobertas de Santos Dumont...
\end{abstract}

Com efeito, sob a égide do processo de modernização, muitas das pequenas profissões de que nos fala João do Rio tende a ser varridas para longe do centro do Rio, outras serão simplesmente extintas, para atender a política urbanística elitista. Os cortiços, por exemplo, tornar-se-ão alvo da política sanitarista conduzida por Oswaldo Cruz. Na verdade,

\begin{abstract}
O saneamento não era só urbano, mas também social, e sobretudo visava o controle do espaço e a criação da cidade burguesa, assim como acontecera em Paris, com Haussmann. Os mais pobres, que viviam nas habitações coletivas, foram expulsos do Centro para habitar as recém-criadas favelas. O desafio de Pereira Passos era transformar a imagem da capital do país de antiga cidade colonial, escravagista, em nova metrópole burguesa cosmopolita, o que ele fez de forma autoritária e violenta. (JACQUES, 2012, p.63)
\end{abstract}

Aos poucos, a metrópole carioca disfarçava os grilhões da colonização e adotava uma estética nos moldes parisienses, travestindo-se de civilizada. No limite, isso também refletia a ascensão da burguesia industrial, bem como a consolidação do Rio como metrópole comercial e bancária. Afinal de contas, até 1907, coube ao Rio à primazia da produção industrial (GORENDER, 2004)

A imprensa também é submetida às novas transformações, desviando o foco das reportagens do plano subjetivo de maneira a atender ao caráter da suposta imparcialidade pautada na objetividade (MORAIS, 2006). João do Rio, nesse novo contexto, não terá problemas para se adaptar, pelo contrário, a partir daí que ele desenvolve melhor seu jornalismo testemunhal, ora demonstrando encantamento, ora 
criticidade, frente à reforma urbana pela qual passava a Metrópole carioca. Assim, entre 11 de agosto de 1907 e 19 de dezembro de 1910, João do Rio, sob o pseudônimo Joe, publica uma série de crônicas no jornal Gazeta de Notícia numa coluna cujo título chamava-se Cinematographo. Nas crônicas o olhar do flâneur captava as cenas da vida urbana como fotogramas, convertendo-as ao final em fragmentos de um mesmo enredo: a vida cotidiana em transformação, implodindo sob a influência de novos referenciais, muitos dos quais externos. João do Rio era o que podemos chamar de cronista do cotidiano, testemunha de transformações urbanas/urbanísticas de uma época ímpar na metrópole carioca.

No livro Cinematographo: crônicas cariocas (2009), publicado homonimamente em 1909, nomeadamente na crônica “Os Humildes”, João do Rio denuncia as condições de trabalho dos operários. De fato, para Gorender (2004), as condições de trabalho da classe operária na primeira república não podiam ser classificadas senão como calamitosas, seja em São Paulo, seja no Rio. Assim nos diz João do Rio:

“(...) exploração da vida humana, do esgotamento de pobres diabos, que nasceram pobres, que vivem pobres e que morrerão, abreviados pelo trabalho, pobres, sem ao menos essa compensação magna: - o dinheiro. (RIO, 2009, p.143)

Estas crônicas foram concebidas a partir da experiência da vida cotidiana, pois para escrevê-las João do Rio recorria a um mergulho profundo na vida dos becos, vielas, ruas estreitas, onde pulsava a vivacidade dos sujeitos subalternizados: carroceiros, carregadores, serventes, que se reuniam nos botequins, esquinas, barbearias, nas ruas... Esses sujeitos são justamente os habitantes das áreas periféricas da cidade, dotados de uma capacidade criativa sem a qual talvez não resistissem frente ao processo de espoliação.

Em grande medida, Baudelaire assim também o fazia, extraindo elementos da vida cotidiana de Paris através da flânerie, como já demonstrara Benjamin (1998). Esteticamente, ainda sob influência hegeliana, Lukács (2009) argumenta - embora noutros termos - que a criação artística é tributária da vida cotidiana, no sentido de ser produto de uma mediação dialética entre objetividade e subjetividade ${ }^{1}$. Em termos dialéticos, podemos pensar num ato sendo reflexo objetivo, mas que também é subjetivamente refletido: 
Na visão ontológica de Lukács, a arte é uma atividade que parte da vida cotidiana para, em seguida, a ela retornar, produzindo nesse movimento reiterativo uma elevação na consciência sensível dos homens. (FREDERICO, 2000, p.302)

Isto é, o processo pelo qual a arte se constrói inicia-se, por um lado, na apropriação do fenômeno pelo sujeito e ao retornar ao vivido nos remete, por outro, a essência da realidade histórico-social na totalidade porque também a transforma: "Toda obra de arte apresenta um duplo caráter em indissolúvel unidade: é expressão da realidade, mas ao mesmo tempo também a produz artisticamente." (KOSIK, 1976, p.128) O artista no seu exercício criativo, porém, não é alheio ao espaço, ao contrário, ele se nutre dele na tomada de consciência (do "em-si" e "para-si") do mundo pela via da linguagem. Ou melhor, o espaço enquanto objetividade, logo é transposto para o plano subjetivo na medida em que se realiza a criação como atividade da práxis humana num processo de objetivação.

Por isso, com vistas para o exercício reflexivo, temos combina-se fenômeno e essência como unidade dialética da práxis humana. (KOSIK, 1976) Em essência, as crônicas de João do Rio nas quais há o hibridismo entre o jornalismo e a literatura desvenda-se as potencialidades criadoras escondidas sob a aparente pobreza do cotidiano; ao invés de abandoná-lo, procura-se extrair dele suas contradições. (LEFEBVRE, 1991) Nas suas flanâncias, notava a existência de outra cidade dentro Rio da belle époque, que naquele instante se reivindicava para si o status de civilidade:

\footnotetext{
Que lugares eram aqueles? O outro mundo! A outra cidade! A atmosfera era aquecida pelo cheiro penetrante e pesado dos grandes trapiches. Em alguns trechos a treva era total. Na passagem da estrada de ferro, a luz elétrica, muito fraca, espalhava como um sudário de angústias. (RIO, 2009, p.32)
}

Eis a contradição do desenvolvimento urbano desigual. Da banalidade, as crônicas nos revelam, com profundidade, a contradição entre a dominação do capital sob égide da modernidade e, ao mesmo tempo, a apropriação do espaço pelo corpo, através das festas, desejo, estética, bem como do ócio expresso na vida boemia. Ao que parece, as crônicas se apresentam como captura do extraordinário no cerne do cotidiano, mas sem necessariamente sair dele.

O cotidiano que se expressa na modernidade anuncia cidades dicotômicas para João do Rio: aquela sob o processo de racionalização produtivista mediante o que ele chama, por exemplo, de polícia dos costumes, cujo centro é uma expressão, avizinhada 
por uma cidade para a qual o urbano é negado, onde ocorrem transgressões, atividades criadoras, enfim, o "outro mundo" por ele ilustrado.

Assiste-se então a conformação de uma cidade como produto em interação dialética com a cidade enquanto obra. $\mathrm{O}$ vivido, neste sentido, é síntese de todo esse processo manipulado como lente de aumento pelo flâneur dos trópicos.

\section{A alma encantadora das ruas}

“A rua conduz o flanador a um tempo desaparecido." (BENJAMIN, 1994, p.185)

Até agora, desenhou-se um João do Rio como um flâneur carioca, deambulando pelo Rio da Belle époque e suas contradições inerentes. Doravante, enseja-se especificamente analisar o método - se é que assim o podemos considerar - de João do Rio na sua prática como jornalista/escritor, baseando-se, para tanto, na sua obra "A Alma encantadora das Ruas".

"A rua se torna moradia para o flâneur que, entre as fachadas dos prédios, sentese em casa tanto quanto o burguês entre suas quatro paredes.” (BENJAMIN, 1994, p.35) Ora, afinal, a rua congrega as passagens, os encontros e, sendo a morada do coletivo é por meio dela, pois, que a experiência urbana se dá mediante a dimensão da corporeidade.

O flâneur, por sua vez, a toma para si a fim não só de observá-la, mas de transmiti-la em narrativas sem, contudo, ignorar sua subjetividade. Parafraseando Benjamin (1994), o flâneur era todo aquele amiúde de origem burguesa que ao desfrutar do ócio, cuja condição confrontava com a divisão social do trabalho, perseguia o cotidiano das grandes cidades, passeando por suas temporalidades, para ver, ouvir, cheirar, isto é, perceber tudo quanto podia a sua volta. Em síntese, a rua é uma précondição da prática da flâneire:

\footnotetext{
Para compreender a psicologia da rua não basta gozar-lhe as delícias como se goza o calor do sol e o lirismo do luar. É preciso ter espírito vagabundo, cheio de curiosidades malsãs e os nervos com um perpétuo desejo incompreensível, é preciso ser aquele que chamamos flâneur e praticar o mais interessante dos esportes - a arte de flanar. (RIO, 2007, p.27)
}

Desse modo, João do Rio, na condição de flâneur, fazia da rua sua morada, pois era nela que se reconhecia e se afirmava, inclusive, enquanto ser social através da arte. Da rua, ele capturava os fotogramas da vida cotidiana sob os quais se disfarçavam as 
contradições imanentes à metrópole carioca. Ao assumir seu papel jornalístico e de escritor João do Rio criava suas crônicas a partir da dimensão fenomênica, deixando entrever, por vezes, a essência fugidia. Para Carlos

\footnotetext{
“(...) na rua se tornam claras as formas de apropriação do lugar e da cidade, e é aí que afloram as diferenças e as contradições que permeiam a vida cotidiana, bem como as tendências de homogeneização e normatização impostas pelas estratégias do poder que subordina o social." (CARLOS, 2007, p.51)
}

À medida que a metrópole carioca ganha contornos de civilidade (nos moldes europeus) e modernização na esteira da homogeneização e normatização, inaugurando uma cotidianidade, tanto mais a relação do artista/jornalista como ela se modifica, suscitando nele estranhamento. $\mathrm{O}$ artista como ser social, a despeito da sua carga subjetiva, cria dentro de condições reais objetivas. Nesse caso, a relação de João do Rio com a rua, enquanto instância objetiva, só reforça isso. Quanto ao estranhamento, diz ele na ocasião da mudança do mercado público:

\footnotetext{
Que nos resta mais do velho Rio antigo, tão curioso e tão característico? Uma cidade moderna é como todas as cidades modernas. O progresso, a higiene, o confortável nivelam almas, gostos, costumes, a civilização é a igualdade num certo poste, que de comum acordo se julga admirável, e, assim como as damas ocidentais usam os mesmos chapéus, os mesmos tecidos, o mesmo andar, assim como dois homens bem vestidos hão de fatalmente ter o mesmo feitio da gola do casaco e do chapéu, todas as cidades modernas têm avenidas largas, squares, mercados e palácios de ferro, vidro e cerâmica. (RIO, 2009, p.153)
}

Em Marx, não resta dúvidas que a consolidação do capitalismo no auge da modernidade representa um momento hostil ao desenvolvimento da arte. A chegada do automóvel aos olhos de Joao do Rio impõe outro ritmo de vida urbano, suprimir da rua os encontros e empobrece a experiência urbana: "Vivemos inteiramente presos ao automóvel. O automóvel ritmiza a vida vertiginosa, a ânsia das velocidades, o desvario de chegar ao fim, os nossos sentimentos de moral, de estética, de prazer, de economia, de amor. (RIO, 2012, p.48)" Depreende-se que a reprodução do capital na vida cotidiana, ao reificar as atividades criadoras, ao empobrecer a experiência urbana, inaugura o reino da banalidade, do consumo, do cíclico, isto é, da cotidianidade. (LEFEBVRE, 1991)

De todo modo, quando na obra se diz alegoricamente que a rua tem alma se reconhece a totalidade embutida essencialmente nela: as relações de trabalho, a técnica, 
a historicidade, sua identidade (ruas honestas, ruas sinistras, ruas sem história, ruas tão velhas que bastam para contar a evolução de uma cidade inteira ${ }^{2}$ ): “A rua nasce, como o homem, do soluço, do espasmo. Há suor humano na argamassa do seu calçamento. (...) conhecendo cada rua, cada beco, cada viela, sabendo-lhe um pedaço da história..." (RIO, 2007, p.16)

Em dado momento, o autor chega mesmo a admitir que a rua - poder-se-ia ampliar a escala para o espaço urbano como um todo - é um forte condicionante da consciência dos tipos urbanos, tanto que muitos destes carregam consigo o nome da rua ou o bairro onde viveram - tal qual ele próprio (João do Rio). É que "a rua é nossa própria existência", diz João do Rio. Com isso, ele nos permite assinalar que não há existência fora das condições reais objetivas a partir das quais a arte é emanada, em síntese, não há arte sem cotidiano. A arte se afirma ontologicamente dentro dessas condições e é por isso uma objetivação da realidade. Isso não significa postular, porém, que a arte deve ser interpretada mecanicamente à luz de um determinismo da vida cotidiana, até porque ela desfruta de uma relativa autonomia, princípio este que o próprio Marx chegou a reconhecer (a arte Grega, por exemplo). Sendo uma via de mão dupla, em termos lukacsianos, a vida cotidiana é fonte e desembocadura da arte. (FREDERICO, 2013)

\section{A pobreza urbana e a vida moderna}

A vida moderna é a expressão da fluidez, de transformações em curto espaço de tempo. Se há alguma certeza na modernidade é a de que não há nada sólido como diria o próprio Marx; ser moderno é conviver com a contínua iminência da dissolução, com o reino da transitoriedade por assim dizer. Durante o processo de modernização urbana, a burguesia constrói e ao mesmo tempo põe abaixo obras públicas, ruas, bairros, cidades inteiras, colocando-os a serviço da reprodução do capital.

A antítese da modernização na metrópole carioca, seu efeito colateral, resulta na pobreza urbana, pois a "benesses" da modernidade - eis apenas uma das suas contradições - é que se trata de um privilégio de classe. Por isso, as formas abstratas do capitalismo - capital, propriedade privada, trabalho assalariado - que vão tomando corpo nesse contexto da modernização do Rio de Janeiro evidencia-se de maneira polarizada e contraditória. Isto é, ao passo em que as áreas centrais são submetidas ao processo de modernização, figurada na construção de amplas avenidas, por exemplo, 
por outro lado os morros e várzeas - áreas mais sensíveis do ponto de vista ambiental começam a ser ocupados por trabalhadores (inclusive, soldados) cuja condição social imposta pela economia capitalista os lança a revelia para o contexto de pobreza urbana, vivendo em habitações precárias, por vezes sem eletricidade, sem um mínimo de infraestrutura básica. Em paralelo, a destruição dos cortiços na esteira do processo de higienização e da política sanitarista no centro tende a intensificar a ocupação dessas áreas mais sensíveis em termos ambientais, as quais, mais tarde, seriam chamadas de favelas. Ao subir o morro Santo Antônio, que dera origem a uma das primeiras favelas do Rio de Janeiro, guiado por uma trupe de seresteiros, descreve João do Rio aquilo que julgou ser uma cidade dentro de uma grande cidade (outro mundo):

Vi, então, que eles se metiam por uma espécie de corredor encoberto pela erva alta e por algum arvoredo. Acompanhei-os, e dei num outro mundo. A iluminação desaparecera. Estávamos na roça, no sertão, longe da cidade. O caminho que serpeava descendo era ora estreito, ora largo, mas cheio de depressões e de buracos. De um lado e de outro casinhas estreitas, feitas de tábua de caixão, com cercados, indicando quintais. (...) Todas feitas sobre o chão, sem importar as depressões do terreno, com caixões de madeira, folhas de flandres, taquaras. A grande artéria da "urbe" era precisamente a que nós atravessamos. Dessa, partiam várias ruas estreitas, caminhos curtos para casinhotos oscilantes, trepados uns por cima dos outros. (RIO, 2012, p.53-55) 


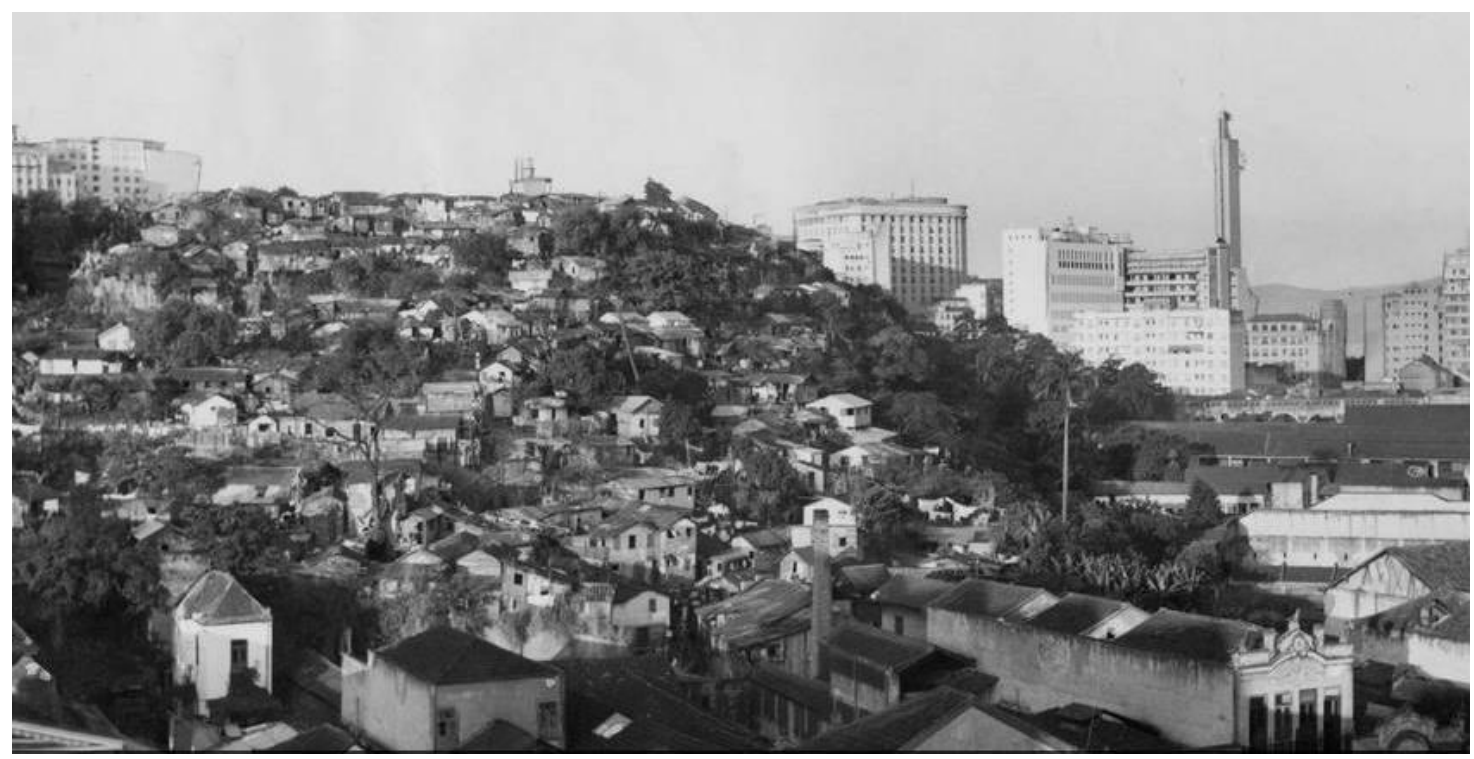

Figura I - Morro Santo Antônio no centro do Rio de Janeiro em 1952.

Fonte: https://acervo.oglobo.globo.com/incoming/morro-de-santo-antonio-av-chile-22212851; acesso em 25 de dezembro de 2019.

Em meados do século XX, o morro Santo Antônio descrito por João do Rio foi sumariamente demolido para a construção da Avenida República do Chile, seus moradores em suas habitações precárias eram tidos como empecilhos para "evolução urbana" que precisava se efetivar sob a égide do urbanismo moderno, cuja racionalidade do tráfego servindo ao homem motorizado em sua pressa cotidiana se impôs aos miseráveis que buscavam no morro a condição necessária para sua existência. A representação de um espaço ordenado e funcional prevaleceu em detrimento do espaço como condição da existência. A técnica, aludindo Benjamin (1994), triunfa sobre a própria existência humana. Afinal, parafraseando Berman (2007), onde se instala a modernidade deixa um rastro de destruição, ela própria é autodestruitiva. A impessoalidade, o individualismo e ritmo acelerado de vida (a pressa de chegar, diria João do Rio) que pesam sobre a vida cotidiana moderna tornam a pobreza parte quase que natural e inevitável da paisagem urbana, um elemento indiferente com a qual temos que conviver como se fosse um efeito colateral legado pelo progresso, mas já socialmente aceito. O empobrecimento da sociabilidade, cada vez mais segmentada do ponto de vista classista, acarretada pelo estilo de vida moderno, turva qualquer sentido humanista que faça com a pobreza urbana seja motivo de indignação e revolta.

Parece que João do Rio está interessado em suas crônicas pelas contradições no seio da modernidade, notadamente pelo embate entre a representação do Rio civilizado à luz da modernidade e a outra parte da metrópole excluída e arrasada por esse projeto, 
ainda que considere os habitantes desta última "seres embrutecidos". Ainda assim, a errância permite a conexão entre espaços apartados, segregados, de modo a correlacionar a pobreza e as privações dos sujeitos subalternizados a uma ordem distante que se instala a partir dos moldes capitalistas. Em “A fome negra”, João do Rio reconhece que o trabalho assalariado "esmaga centena de homens" que por vezes ultrapassavam às dez horas de trabalho descarregando carvão e manganês, recursos estes a serviço de uma ordem distante que os explora, pois diz o cronista, "o manguanês, que a Inglaterra cada vez mais compra do Brasil, vem de Minas até a Marítima em estrada de ferro; daí é conduzido em batelões e saveiros até as ilhas Bárbaras e da conceição, onde fica o depósito" (RIO,2012,p.37).

A obra de João do Rio não traduz apenas uma época específica (belle époque) do Rio de Janeiro, contempla também uma geografia da vida cotidiana moderna, afinal "lançando-se no caos da vida cotidiana do mundo moderno - uma vida de que o novo tráfego é símbolo primordial -, o poeta pode apropriar-se dessa vida para a arte." (BERMAN, 2007, p.191)

\section{Para não concluir}

Sem nenhuma pretensão conclusiva, ensejou-se aproximar a obra de João do Rio com a as condições objetivas, no espaço-tempo, a partir das quais sua arte ganhava corporeidade. Observou-se, portanto, situar o lugar que ocupa o cotidiano em suas crônicas, bem como a rua enquanto espaço de encontro.

Em geral, na Geografia ainda são incipientes os estudos em que o espaço alcança uma dimensão constitutiva da estética, salvo no âmbito da geografia cultural sob o enfoque do método fenomenológico. Em geral, se tem procurado analisar o espaço dentro das narrativas fílmicas, literárias, musicais, mas pouca importância se tem atribuído a ele na relação - sempre dialética - entre objetividade e subjetividade no plano da estética como um todo. Ademais, há um gargalo no que diz respeito aos estudos estéticos, pois neles o espaço é geralmente escamoteado, ficando alheio à atividade criadora.

Para superar essa condição dificilmente encontraremos referenciais na Geografia, sendo imperativo dialogar com autores da filosofia para os quais a estética é tomada, ao mesmo tempo, enquanto reflexo da concreticidade, reiteradamente refletida 
no real, na medida em que se expressa como objetivação e se torna autoconsciência do desenvolvimento da humanidade (LUKÁCS, 1992). Nas palavras de Marx:

O objeto artístico - bem como qualquer outro produto - cria um público sensível à arte e capaz do prazer estético. A produção, por isso, produz não apenas um objeto para o sujeito, mas também um sujeito para o objeto. (MARX Apud LUKÁCS, 1992, p.199)

A obra de João do Rio resulta de uma tomada de consciência do mundo objetivo e ao retornar para este contribui para elevação da autoconsciência humana por meio da experiência do sujeito receptivo - nesse caso, inserem-se o autor e o leitor do ensaio -, que se configura num processo do ser em-si da objetividade no ser para-nós.

\section{Notas}

1 - O autor aprofunda a discussão na sua teoria do reflexo contida no livro "Arte e Sociedade: escritos estéticos 1932-1967. Organização, apresentação e tradução Carlos Nelson Coutinho e José Paulo Netto. Rio de Janeiro: Editora UFRJ, 2009.

2 - RIO, 2012, p.23.

\section{Referências}

BASALLA, George. The spread of western science. Science, v. 156, n. 3775, p. 611622, 1967.

BENJAMIN, Walter. Obras escolhidas Vol. III. Charles Baudelaire, um Lírico no Auge do Capitalismo. Trad. e org. de José Carlos Martins e Hermerson Alves Baptista. São Paulo: Brasiliense, 1994.

BERMAN, Marshall. Tudo que é sólido desmancha no ar. São Paulo: Companhia de Bolso, 2007

CARLOS, Ana Fani Alessandri. O lugar no/do mundo. $1^{\circ}$ ed. São Paulo: Labur Edições, 2007.

"Novas" contradições do espaço. In: DAMIANI, Amélia Luisa et al.(org.) O espaço no fim de século: a nova raridade. São Paulo: Contexto, 1999, pp. 62-74

COUTINHO, Giulliano. Reflexões sobre a geografia e sua história no Brasil: notas para um caminho historiográfico'. In: II Encontro Nacional de História do Pensamento Geográfico, 2009, São Paulo. Anais do II Encontro Nacional de História do Pensamento Geográfico, 2009.

FREIRE, Paulo. Pedagogia do Oprimido. Rio de Janeiro: Paz e Terra, 2011, 50. ed. FREDERICO, Celso. Cotidiano e arte em Lukács. Estudos Avançados, São Paulo, v.14, n.40, p. 299-308, 2000. 
2013.

A arte no mundo dos homens. São Paulo: Expressão Popular,

FERREIRA, Alvaro. Influência europeia ou mera cópia? A produção do espaço no Rio de Janeiro. Scripta Nova. Revista Electrónica de Geografía y Ciencias Sociales. [En línea]. Barcelona: Universidad de Barcelona, 1 de noviembre de 2012, vol. XVI, nº 418 (42)

GORENDER, Jacob. A burguesia brasileira. São Paulo: Brasiliense, 2004.

JACQUES, Paola Berenstein. Elogio aos errantes. Salvador: EDUFBA, 2012.

KOSIK, Karel. Dialética do concreto. Trad. NEVES, Célia; TORÍBIO, Alderico. Rio de Janeiro: Paz e Terra, 1976.

LACOSTE, Yves. A Geografia-Isso serve em primeiro lugar para fazer a guerra. 5.ed. São Paulo: Papirus, 2001.

LEFEBVRE, Henri. A vida cotidiana no mundo moderno. São Paulo: Ática, 1991.

La producción del espacio. Tradução de EmilioMartínez Gutiérrez.

Madrid: Capitán Swing, 2013. 451 p. Título original: La production de leespace.

LUKÁCS, György. Arte e Sociedade: escritos estéticos 1932-1967. Organização, apresentação e tradução Carlos Nelson Coutinho e José Paulo Netto. Rio de Janeiro: Editora UFRJ, 2009.

Sociologia. In: NETTO, J. P. (Org.). Grandes cientistas sociais, São

Paulo: Ática, n. 20, 1992.

MORAES, Antonio Carlos Robert. "Notas sobre identidade nacional e institucionalização da Geografia no Brasil”. In: Estudos Históricos, Rio de Janeiro, v. 4, n. 8, p. 166-176, 1991.

RIO, João do. Cinematógrafo (Crônicas Cariocas). Rio de Janeiro: ABL, 2009.

A alma encantadora das ruas. São Paulo: Editora Martin Claret, 2007. . João do Rio, Uma Antologia (seleção e apresentação de Luís Martins)

5 ed. Rio de Janeiro: José Olympio Editora, 2012.

SOUZA NETO, Manoel Fernandes de. "Geografia nos Trópicos: memória dos n áufragos de uma jangada de pedras?” In: Revista Terra Livre, nº 17. São Paulo: AGB, p. 119-137, julho/dezembro de 2001. 